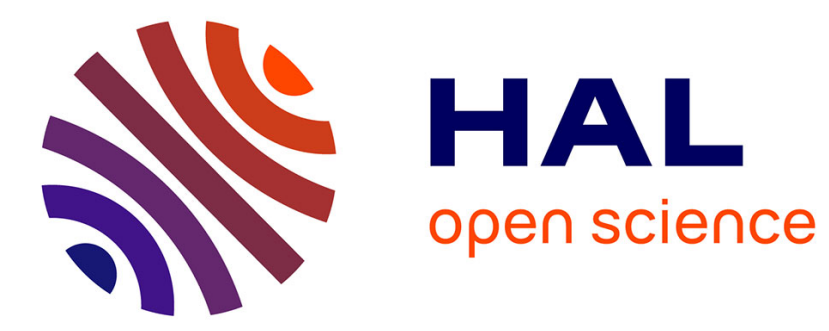

\title{
Methods for PDO olive oils traceability: state of art and discussion about the possible contribution of strontium isotopic tool
}

\author{
Myriam Janin, Salim Medini, Isabelle Techer
}

\section{- To cite this version:}

Myriam Janin, Salim Medini, Isabelle Techer. Methods for PDO olive oils traceability: state of art and discussion about the possible contribution of strontium isotopic tool. European Food Research and Technology, 2014, 239, pp.745-754. 10.1007/s00217-014-2279-8 . hal-01539820

\author{
HAL Id: hal-01539820 \\ https://hal.science/hal-01539820
}

Submitted on 12 Jul 2017

HAL is a multi-disciplinary open access archive for the deposit and dissemination of scientific research documents, whether they are published or not. The documents may come from teaching and research institutions in France or abroad, or from public or private research centers.
L'archive ouverte pluridisciplinaire HAL, est destinée au dépôt et à la diffusion de documents scientifiques de niveau recherche, publiés ou non, émanant des établissements d'enseignement et de recherche français ou étrangers, des laboratoires publics ou privés.

\section{(ㅇ)(1) $\$$}

Distributed under a Creative Commons Attribution - NonCommercial - NoDerivatives| 4.0 


\title{
Methods for PDO olive oils traceability: state of art and discussion about the possible contribution of strontium isotopic tool
}

\author{
Myriam Janin · Salim Medini · Isabelle Técher
}

\begin{abstract}
Olive oil represents an important ingredient in the Mediterranean diet and is appreciated both for nutritional and sensory properties, often related to geographical origin and cultivar of olive fruits employed. Fraudsters trying to seek financial gain can adulterate the product causing economic repercussions and, sometimes sanitary risks. The "protected designation of origin" (PDO) label insures a relative protection of both consumers and honest producers, since it prescribes production techniques and specific geographical origin, but one of the main problems is to set down objective tools to control these specifications. We reviewed numerous studies using various analytical tools to discriminate PDO olive oils' geographical origin depending on (1) volatiles compounds, (2) fatty acid and triacylglycerol composition, (3) trace elements, and/or (4) stable isotope ratios, but we highlighted that, despite their efficiency, none of them could provide an irrefutable identification. However, ${ }^{87} \mathrm{Sr} /{ }^{86} \mathrm{Sr}$ signature revealed to be an optimal geographical fingerprint in the same purpose for other food products like cereals, orange juice, coffee or alcoholic beverages. Such ${ }^{87} \mathrm{Sr} /{ }^{86} \mathrm{Sr}$ studies do not exist on olive oils, probably because of analytical issues, but we propose that developing complementary ${ }^{87} \mathrm{Sr} /{ }^{86} \mathrm{Sr}$ studies could be a promising tool to reenforce the characterization of PDO olive oils.
\end{abstract} Analytical methods . Geographical origin . Fraud .

M. Janin $(\bowtie) \cdot$ S. Medini · I. Técher

Laboratoire de Géochimie Isotopique

Environnementale (GIS)/CEREGE, CNRS-UM 34,

Université de Nîmes et d'Aix-Marseille, 150 rue

Georges Besse, 30035 Nîmes Cedex 1, France e-mail:

myriam.janin@unimes.fr

S. Medini e-mail:

medinisalim88@yahoo.com

I. Técher e-mail:

isabelle.techer@unimes.fr

Keywords Olive oil - Protected designation of origin · 


\section{Introduction}

Over the years, recognition of food authenticity has become an important issue in terms of quality and safety control of food products. Due to specific characteristics enhancing a high quality, such as the geographical origin and/or production processes, some products have higher market prices. Consequently, fraudsters trying to seek financial gain can aim to adulterate food by improperly mislabeling products, mixing high-quality ones with sub-standards, and/ or non-observing specific production processes. In addition to economic aspects, such adulteration can sometimes cause severe risks for the public safety. For these reasons, to protect consumers and honest producers and to protect prescribed production techniques and specific geographical origin, the European Union Protected Food Name Schemes came into force in 1992 [1]. Legal regulations now require a labeling system for the protection of food names on a geographical basis. One of the three existing schemes is the protected designation of origin (PDO) used to describe foodstuffs production, processes and treatments using prescribed techniques in a specific geographical area. The other ones are (1) the protected geographical indication (PGI), for products having a geographical link in at least one of the stages of production, processing or preparation and (2) the certificate of specific character (CSC, also known as Traditional Specialty Guarantee) which not refers to a specific geographical origin, but defines traditional character in terms of production techniques or composition. to be defined. These controls require the selection of specific compositional markers to trace any food samples from the producer to the consumer and ascertain what is claimed on the previously cited labels.

Strategies employed to detect fraudulent food products thus cover many different aspects and can be relied on various analytical methods. The PDO-approved agricultural products and foodstuffs that are produced, processed and prepared in a given geographical area, using a recognized know-how, are related to official specifications. Studies published on food authentication are usually based on food composition, which may vary with soil characteristics, vegetal variety, growing conditions, climate and/or fertilization. Such authentications are not irrefutable on the identification of the geographical origin and usually require comparative indicators. Consequently, they are more "discrimination" between original and fraudulent products, than real "identification" of the geographical origin, that is to say the characterization of a specific geographical area of the foodstuff production. This "identification" issue has been resolved for some agrifood products such as rice [2], wines [3-5] and coffee [6], using of ${ }^{87} \mathrm{Sr} /{ }^{86} \mathrm{Sr}$ isotopic ratio as geographical traceability marker. ${ }^{87} \mathrm{Sr} /{ }^{86} \mathrm{Sr}$ ratio could be an optimal geographical fingerprint for food since (1) ${ }^{87} \mathrm{Sr} /{ }^{86} \mathrm{Sr}$ is a parameter reflecting local geological and geochronological settings and (2) strontium is actively involved in the metabolism of bio-organisms, and biological processes do not significantly fractionate strontium isotopes [7].

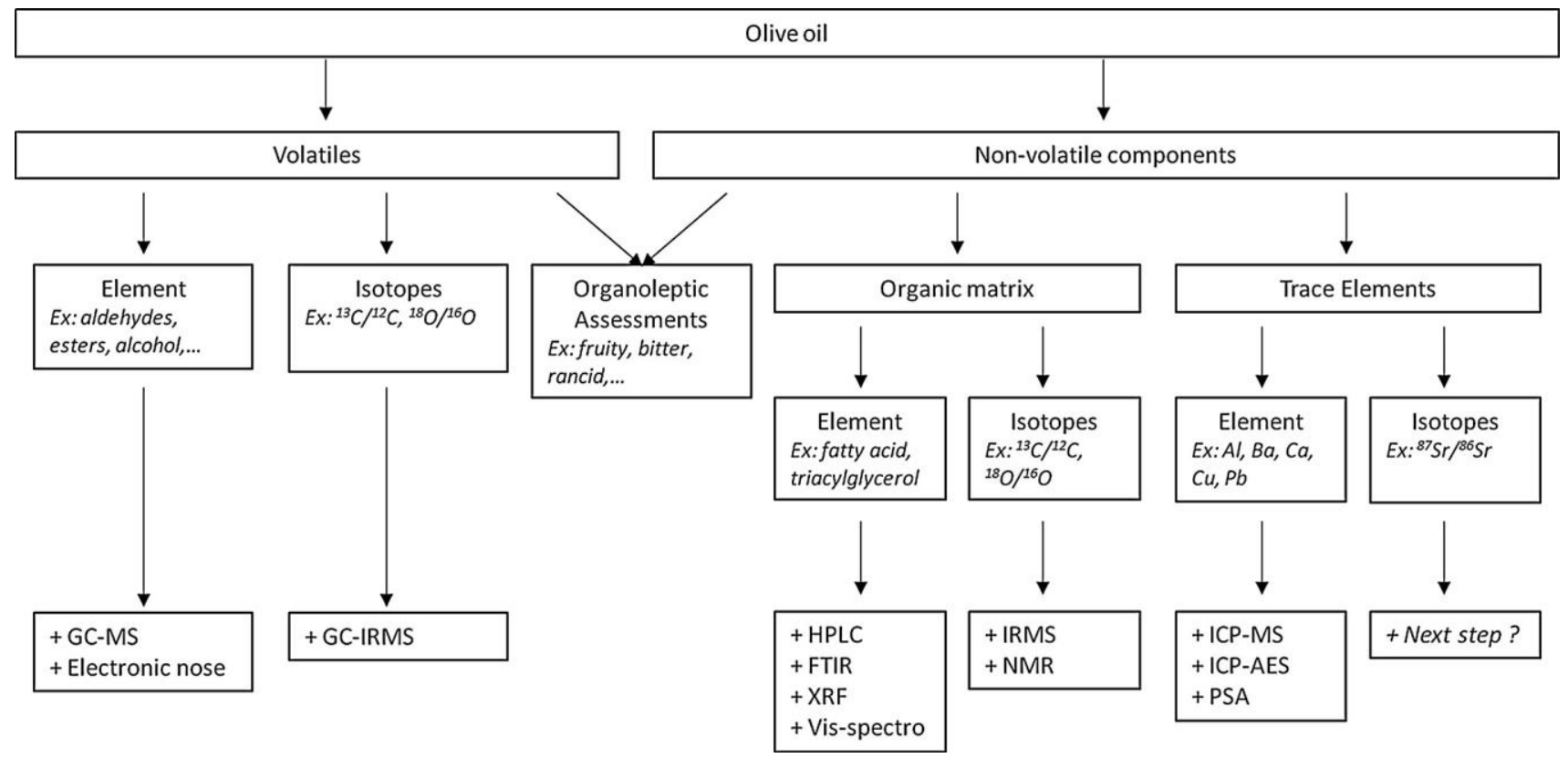

Fig. 1 Summary of existing methods to discriminate olive oils geographical origin. See text for specification and examples for each of them To insure a real application of these laws, control tools have 
Extra virgin Olive oil represents an important ingredient in the Mediterranean diet [8] and is appreciated both for nutritional and sensory properties, often related to geographical origin and cultivar of olive fruits employed. Mediterranean countries are the largest olive oil producers. Indeed, data collected from 1961 to 2006 point out that Spain, Italy and Greece took together account for around three-quarters of all olive oil produced worldwide [9]. Consequently, olive oil quality and purity is important from the possible repercussions on the economy of

Mediterranean countries, but is also important from a nutritional point of view since epidemiological studies provided evidences that consumption of virgin olive oil contributes to the lower incidence of coronary disease due to the presence of some antioxidant micronutrient. Many types of extra virgin olive oils are produced by mixing from different cultivar, but numerous growers have chosen high-quality production and European labeling in order to satisfy consumer requirements. PDO olive oils refer to specific areas and process of production, and one of the major issues is the traceability from the producers to the consumers. To guarantee this high-quality traceability, a specific regulation applies [10] and numerous accurate and sensitive analytical methods are developed in order to insure product authenticity. The different methodologies range from "simple" organoleptic characterization, to DNA markers, volatiles compounds, trace element contents and light isotopes ratios [11]. The aim of this paper is (1) to provide an overview of existing methodology for discrimination of PDO in olive oils (summarized in Fig. 1), with a focus on their respective strengths and weaknesses, (2) to discuss the promising results given by ${ }^{87} \mathrm{Sr} /{ }^{86} \mathrm{Sr}$ identification on various food products and (3) to evaluate the existence and feasibility of complementary ${ }^{87} \mathrm{Sr} /{ }^{86} \mathrm{Sr}$ studies on olive oils.

\section{Organoleptic characteristics}

The sensorial quality of a virgin olive oil is determined by a series of positive (fruity, bitter, pungent) and negative (fusty, winey-vinegary, musty, muddy, rancid) attributes that characterized it. The intensities of these olive oil attributes are quantified by trained assessors able to discriminate oils specificities. The official methodology is called panel test and is regulated by the International Olive Oil Council (IOOC) trade norm [12] and the European Commission Regulation [13]. The aim of the assessors is to provide an intensity scale of each characteristic (fruity, bitter, etc....). The European commission provides a decision tree according to which the testing laboratory (recognized by the IOOC) can verify whether an olive oil is consistent with a certain category or not [12].

Oil quality is directly related with both agricultural aspects (olive fruit quality, grade of ripeness, handling during harvesting [14]) and manufacturing practice (oil processing, storage condition [15]). The organoleptic evaluation of olive oil thus is a very important consideration regarding a consumer's refusal toward defect-free oils, but oil's rejection may be an objective issue, and not just a matter of preferences. For instance, Perez-Camino et al. [16] revealed that the use of olive fruits with fermentive alteration causes the increase in concentration of fatty acid alkali esters (FAAEs), resulting in musty, winey-vinegary or muddy attributes. Gomez-Coca et al. [17] related the FAAEs concentrations of olive oil with sensory classification and established a connection between the presence of large quantities of FAAEs and fermentative organoleptic defects. In the same way, Lopez-Feria et al. [18] quantified the main sensory defect and one positive attribute of virgin olive oils using the direct coupling headspace-mass spectrometry (HS-MS) and multivariate calibration techniques. Even if instrumental alternatives must be developed to get further these first appreciations, sensory determination remains a fundamental method that is notably able to mark negative sensorial attributes.

The main point here is that low-quality olive oils with weak organoleptic defects are often the objects of illegal practices opposite to PDO requirement (e.g., process and production in a given geographical area using recognized know-how). However, even if the use of sensory attribute is successful to detect adulteration of oil samples, its capability to provide clear identification seems limited. Indeed, this sensorial analysis may include several disadvantages such as: lack of references standards, problems of correspondence of intensity between attributes of complex blends, poor repeatability and subjectivity [19]. Moreover, this method requires the adequate panelist's training, which can turn out to be lengthy and expensive.

Olive oil is one of the rare food products that undergo a standards sensory evaluation on top of chemical analysis. Unfortunately, this information is largely insufficient for characterizing this oil in the frame of PDOs. No chemical parameter is set for PDO traceability and authentication of olive oils [13], but in the past few years, numerous studies reported on use of analytical tools for discrimination of PDO products (detailed in next section). These studies were performed using extremely varied physical-chemical determinations, often in association with chemometric analyses. 


\section{Chemical characteristics}

Volatiles

The sensorial attributes of olive oils are mainly generated by volatile constituents including carbonyl compounds (aldehydes, ketones, etc....), alcohols, esters and hydrocarbons [20, 21]. These attributes may have a high influence on the flavor of olive oil $[22,23]$. Thereby, the potential discrimination of geographical origin of olive oil can be based on their volatile profile characterization [24, 25]. The detection of volatile compounds can be achieved either by analytical techniques such as gas chromatographymass spectrometry (GC-MS) or by electronic gas sensor array system commonly called "electronic nose."

Most of the techniques directed to the identification and quantification of volatiles constituents are related to the analysis of the headspace of the sample through GC-MS, eventually with some specific variant. The headspace (HS) technique analyzes the vapors (gas phase) in equilibrium with the oil (liquid phase) and requires GC-MS coupled with direct thermal extraction [26] or solid-phase microextraction (SPME) [23, 27-29]. This technique allows the detection of numerous volatile species such as aldehydes, terpenes and alcohols. Depending on the specific concentration of these substances, they give the specific aromatic profile of one olive oil. For instance, hexanal and nonanal (aldehydes family) give an herb olive aroma [21, 30], while ethanol gives the smell of ripened olive [31]. In the frame of oil characterization, the HS-MS techniques has been applied with success for the determination of adulteration such as mixing of olive oil with hazelnut oil, sunflower oil and/or olive-pomace oil [32,33], the detection of contaminants (such as benzene, toluene, ethylbenzene, xylene isomers and styrene [34] and the differentiation between different geographical origin, as for instance for extra virgin olive oils from different Mediterranean areas [35].

GC-MS techniques are expensive and time consuming, so a variety of new sensor devices, as well as news techniques, recently emerged to help manufacturer in the field of quality control. Several studies demonstrated the potential of electronic nose in food-relevant applications for the quality control of olive oil [36, 37] and for the verification of geographical origin $[24,25]$. The interaction of volatiles on the sensing element causes changes in electrical resistance of the sensor, changes converted into odor fingerprint and then interpreted using the appropriate mathematical technique. When compared to the classic method (GC-MS and companion techniques), the electronic nose seems to be a powerful complementary tool and provides promising perspectives for the use of a low-cost and rapid system for the verification of the quality and geographical origin of the olive oils according to their volatile profile [25, 38]. For instance, Haddi et al. [25] pointed out the efficiency of the approach in the discrimination of Moroccan olive oils samples produced from olive cultivars in five different areas. The methodology also provides such discrimination among a same olive oil variety [38].

\section{Organic matrices}

Previous studies demonstrated the feasibility of olive oils characterization using their fatty acid and triacylglycerol compositions [39-42]. Because of the variability in fatty acid (oleic, linoleic, palmitic, stearic ...) and triacylglycerol (e.g., three fatty acids carbon chains fixed on a glycerol group) compositions in oil samples, statistical methods can be used to describe PDO characteristics. Such chemometric treatments are detailed hereunder.

To determine the origin of five French olive oils recognized by a RDO (registered designations of origin that is a French designation) or a PDO, Ollivier et al. [40, 42] performed separate analyses of their fatty acid and triacylglycerol composition. This approach was realized on different olive oil varieties. First, olive oil samples in nheptane were transmethylated with a cold and fatty acid methyl esters (FAME) and analyzed on a gas chromatograph (GC) equipped with a split/split-less injector and flame ionization detector (FID). Triacylglycerols were analyzed by a high-performance liquid chromatography (HPLC) system where a separation in a flow rate linear gradient according to the specific carbon composition. Triacylglycerol-specific identification was carried out with the help of standards and by comparison with literature data. A linear discriminant analysis (LDA) applied to the resulting dataset (given as a $\%$ of the total composition) allowed a good discrimination between samples of French olive oils from different areas. Ollivier and co-workers studies demonstrated that it was possible to characterize olive oils from the same country using their fatty acid and triacylglycerol compositions, but only samples with different varietal compositions were perfectly differentiated. Samples with varieties in common were misclassified implying that fatty acid and triacylglycerol composition of olive oils cannot be used as a single geographical "marker as evidenced by other studies on fatty acid composition" [39, 41].

Fourier transform infrared (FTIR) spectroscopy is a rapid and nondestructive analytical tool for the study of oils, which requires a minimal sample preparation. FTIR is also an excellent tool for quantitative analysis since the intensities of spectral bands are proportional to 
concentration. For this reason, FTIR has been used, among others, to distinguish olive oils from different geographical origin [43-45].

FTIR spectra are obtained from the absorbance at infrared wavelengths of an olive oil thin film created by direct deposit between two well-polished disks. Each selected spectral region (peak or shoulder) represents a structural or functional group information, either about the lipids or minor components of the oil samples. This technique is especially powerful to highlight mixing of olive oil with low-cost edible oils. Consequently, FTIR is mainly used to detect adulteration and to establish the authenticity of olive oil, as well are near-infrared spectroscopy (NIR) [46-48] and Fourier transform Raman spectroscopy (FT-Raman) [47, 49]. For example, Bendini et al. [44] determined free fatty acid (FFA) content on 84 monovarietal olive oil samples from eight Italian regions and combined their results to multivariate analysis to discriminate the majority of the samples coming from three of them (Emilia Romagna, Sardinia and Sicilia). In the same way, De Luca et al. [45] succeeded in the classification of different olive oils produced from the same variety, but in several regions (areas) in Morocco.

$\mathrm{X}$-ray fluorescence (XRF) is a well-established analytical technique for the determination of trace, minor and major elements, in a large variety of matrices [50]. However, the determination of organic content by XRF remained a difficult task since the X-ray cross sections for light elements are very low. However, Bortoleto et al. [51] developed an innovate technique based on X-ray scattering and using principal component analysis (PCA) to classify complex organic matrices of different vegetable oils. With this new procedure, the $\mathrm{X}$-ray spectra are processed through PCA, and a classification is obtained as a function of the nature of the oil (olive, corn, soybean...). However, this classification is not performed for geographical discrimination, but to verify oil adulteration (water addition...) with the possibility of distinguishing different types of oil having variable fatty acids contents (corn, soybean, olive, etc.). Finally, this procedure seems to be very promising, especially with the possibility of performing in situ measurements with a portable instrument, but the issue of PDOs authentication remains.

Recently, Pizarro et al. [52] proposed a strategy to evaluate the potential of visible spectroscopy fingerprints combined with multivariate data analyses in the discrimination of Spanish olive oils regarding their geographical origin. Indeed, the potential of UV-visible spectroscopy as fingerprint technique in combination with chemometrics had been examined recently on wines [53] or coffees [54] and seems to be another alternative for reducing cost and time in samples preparation and analysis. Pizarro et al. [52] obtained a perfect discrimination between the defined categories after performing PLS and LDA (see later for details) on samples of various varieties and areas, which emphases the feasibility of the proposed strategy.

\section{Trace element}

The normal range of organic compounds in food may vary with fertilization, climatic conditions and history of the field, species, as well as geographical location and soil characteristics. Taking into account all these imprints, it is sometimes difficult to consider only organic compounds to discuss the authenticity of a food [55]. Consequently, the content of selected minerals and trace elements, known to reflect the environmental growing conditions, proved to be useful to discriminate the geographical origin of food samples such as wine [56, 57], potatoes [58-60], pistachios [61] or even PDO cheese samples [62].

Jimenez et al. [63] assumed a correlation between the elemental content of Spanish olive oils and their origin and performed a pilot study on the geographical characterization of these oils using trace elements contents. Trace elements in fat and oils are particularly difficult to analyze, and usually, they required a massive sample treatments in order to eliminate the organic matrix (wet, dry or microwave digestion) because of negative effects on inductively coupled plasma techniques analyses. However, alternative techniques are available for introduction of oil samples directly into the ICP, such as online emulsification. The analytical procedure used inductively coupled plasma- mass spectrometry (ICP-MS) for multielemental determination of $\mathrm{Al}, \mathrm{Ba}, \mathrm{Bi}, \mathrm{Ca}, \mathrm{Cu}, \mathrm{Mn}, \mathrm{Pb}$ and $\mathrm{Sn}$, coupled to a flame atomic absorption spectrometer (FAAS) for the determination of $\mathrm{Na}, \mathrm{K}$ and $\mathrm{Mg}$ (because of numerous interferences by ICP-MS). The statistical analysis carried out showed that $\mathrm{Al}, \mathrm{Ba}$ and $\mathrm{Mn}$ have a differentiating ability, which permits separation of olive oils from different Spanish cultivars according to their geographical origin.

However, in 2005, Zeiner et al. [64] used atomic emission spectrometry (ICP-AES) and electro thermo atomizationatomic absorption spectrometry (ETA-AAS-for concentrations below the LOD of ICP-AES) in the same sample digest and analyzed $\mathrm{Al}, \mathrm{Ca}, \mathrm{Co}, \mathrm{Cr}, \mathrm{Cu}, \mathrm{Fe}, \mathrm{K}, \mathrm{Mn}$, $\mathrm{Na}, \mathrm{Ni}, \mathrm{Pb}$ and $\mathrm{Zn}$ contents. They highlighted differences in $\mathrm{Al}, \mathrm{Co}, \mathrm{Cu}, \mathrm{K}$ and $\mathrm{Ni}$ contents according the geographical origin of fourteen Croatian olive oils. Consequently, multielemental measurements seem to be a powerful tool of discrimination between different olive oils when associated to statistical data analysis to extract the relevant information.

Since then, numerous studies used ICP or AAS techniques to check the authenticity of olive oils in terms of 
geographical origin such as Benincasa et al. [65] on Italian oils (ICP-MS equipped with a dynamic reaction cell), Carmen et al. [66] on Spanish oils (ETA-AAS) or Araghipour et al. [67] on oils from five different European countries (proton transfer reaction-MS). These approaches sometimes succeeded in the recognition of an olive oil country of origin, but were not decisive in terms of traceability from a specific area of production.

In the same way, the presence of trace metals in olive oils may be due to both endogenous factors (like plant metabolism) and environmental factors, so the heavy metals composition alone could reflect a specific geographical origin. Some specific techniques such as potentiometric stripping analysis (PSA) were performed to detect heavy metals. However, Farhan et al. [68] showed that the composition in heavy metals may be altered during production processes (oil extraction, packaging ...) and cannot be representative of the origin of the product. Consequently, PSA-similar analyses are limited to the determination of some trace metals of nutritional and toxicological interest $[69,70]$.

\section{Chemometric methods}

Volatiles content, organic components, trace element profile and all possible chemical descriptors were used to establish differences between PDOs olive oils. Due to the large number of variables involved, multivariate data analysis was required to extract the relevant information. Two types of statistical procedures may be applied to discriminate the sources of variability. The "untargeted method" consists in a samples classification without any a priori knowledge of their origin, while a "targeted method" is used to establish the similarity of an unknown sample toward authentic material.

The most common untargeted procedures used are:

(1) The PCA: the objective is to identify in the hyperspace of the variable the direction, on which most of the information is retained. In other words, using projections of the dataset, it is possible to demonstrate similarities and differences by determining at the same time, which variables are principally involved $[28,51$, 63].

(2) The cluster analysis (CA): the objective is to group the objects in clusters by measuring the distance or the similarities between them, with the assumption that the nearness of objects is correlated with the similarity of their properties [45].

(3) The analysis of variance (ANOVA): the objective is to analyze the differences between two or more group means [71].
The most common targeted procedures used are:

(1) The LDA: is based on the assumption that the samples distribution is multivariate normal, and the covariance matrix of each category is not significantly different from one case to another. In other words, the samples are assigned to the category with the lowest differences in the hyperspace of the previously identified variables. The limit between two categories is a linear function $[42,65,72]$.

(2) The partial least square (PLS): is an asymmetric method establishing a correlation analysis between two dataset and permitting to predict one set from another by estimating the values of one variable from a set of independent variables $[18,52]$.

All these methods have been applied to discriminate olive oil samples from different geographical origin. They may be applied on volatiles, organic or trace elements profiles, as well as stable isotope ratios.

\section{Stable isotope ratio}

It is now established that the content of selected volatiles, molecules or selected elements in olive oils reflects the soil type, the environmental growing conditions and the manufacturing processes, allowing discrimination depending on their geographical origin. The most frequently occurring elements in organic matrices do not include radioactive isotopes, so the content in stable isotopes of different origin may reflect local agricultures practices and climatic characteristics and thus may provide unique and representative fingerprints reliable to different PDOs. Because of that, stable isotope ratio (SIR) has been demonstrated to be a good descriptor for different food products [73]. In case of olive oils, Carbon, Oxygen, Hydrogen and Phosphorus isotope ratios have been used with success for the characterization of their geographical origin. Mainly, by combining stable isotopes and element data, a good discrimination between various varieties of olive oils can be obtained [74].

Mass spectrometer (MS) and nuclear magnetic resonance (NMR) are useful technique for acquiring data on the origin of food products [55]. Mass spectrometry previously described (e.g., ICP-MS) does not usually provide the sensitivity or the precision required to detect slight differences in natural isotopic abundance. Such precise measurements thus require a Multicollector magnetic sector mass spectrometer, also called isotopic ratio mass spectrometer (IRMS). IRMS is often used for ${ }^{13} \mathrm{C} /{ }^{12} \mathrm{C}$, ${ }^{15} \mathrm{~N} /{ }^{14} \mathrm{~N}$ and ${ }^{18} \mathrm{O} /{ }^{16} \mathrm{O}$ by measuring their atomic mass 
according to magnetic deviation. Several interfaces exist to introduce samples into the IRMS. The most commonly used are elemental analyzers (EA-IRMS) and gas chromatographs (GC-IRMS). EA-IRMS involves a sample pre-treatment and is appropriate for the analysis of nonvolatile substances (e.g. fatty acids for example). However, while EA-IRMS provides only an average value for the entire sample, GC-IRMS can provide additional information by analysis of a complex mixture. GC-IRMS exhibits a higher discriminatory power by implies a volatile form of the samples.

The ${ }^{13} \mathrm{C} /{ }^{12} \mathrm{C}$ may be measured using EA-IRMS or gas chromatography/combustion-IRMS (GC/C-IRMS) in bulk olive oil or in some sub-component such as individual fatty acids. Royer et al. [75] suited the fatty acids ${ }^{13} \mathrm{C} /{ }^{12} \mathrm{C}$ of French, Italian and Greek olive oil samples and achieved a regional classification of the Greek ones. Angerosa et al. [76] evidenced a relation between ${ }^{13} \mathrm{C} /{ }^{12} \mathrm{C}$ and ${ }^{18} \mathrm{O} /{ }^{16} \mathrm{O}$ and latitude of olive oils from Italy, Greece, Spain, Tunisian, Morocco and Turkey, suggesting as cofactors of variability the distance from the sea and environmental conditions during the growing of plants. This confirms that these SIRs are good tools for characterizing the geographical origin of different olive oils, assuming that they are correlated with the climatic and geological characteristics of the country of origin.

NMR allows the measurement of, among others, ${ }^{1} \mathrm{H},{ }^{13} \mathrm{C}$ and ${ }^{31} \mathrm{P}$ and is commonly used in combination with IRMS for SIR measurements [55]. NRM is less sensitive than MS (ng range instead of pg range for MS), but allows the detection of important nuclides from organic compounds such as ${ }^{1} \mathrm{H}$. Consequently, ${ }^{1} \mathrm{H}$ and ${ }^{13} \mathrm{C}$ NMR fingerprints are commonly investigated in olive and may be combined with chemometric analysis for the classification and the prediction of the geographical origin [77-81]. Petrakis et al. [82] add ${ }^{31} \mathrm{P}$ to ${ }^{1} \mathrm{H}$ NMR fingerprint to characterize Greek virgin olive oils. Recently, Dais and Hatzakis [83] provided a critical review of NMR method to characterize olive oils in terms of quality, adulteration, geographical origin and botanical origin. They listed numerous studies for the discrimination of PDO olive oils on a regional (sites with the same geographical region), national (different region within the same country) and even on an international scale. One of their main conclusions is that there is no integrated approach to obtain irrefutable information about PDOs on a national, and perhaps international scale, since a multitude of factors has to be taken into consideration, like pseudoclimatic conditions (climate, soil, etc.) ripeness of olives closely connected with the time of collection, genetic factor (cultivar) and/or agronomic conditions (irrigation).

Studies with other chemical tracers (see previous sections) lead to the same conclusion. Many factors influence the food composition, which often limits a real authentication (e.g., identification) of PDOs products to only discriminate known samples.

\section{Next issue: identifying instead of discriminating the geographical origin}

As evidenced, traceability and authenticity of olive oils have been the objects of numerous studies using various physical-chemical determinations in association with chemometric analyses. However, none of these characteristics seems to be irrefutable in the identification of the geographical origin of these oils without comparative indicators. Such issues have already been resolved for other food products such as dairy products $[84,85]$, rice [2-86], cereals [87], meat [88], orange juice [89], coffee [6,90] and alcoholic beverages [3, 5, 91]. Among the studied parameters, the ratios of the isotopic abundances of light $(\mathrm{H}$, $\mathrm{C}, \mathrm{N}, \mathrm{O}, \mathrm{S}$ ) and $\mathrm{Sr}$ elements provided the best promising results for these purposes. In these last years, the ${ }^{87} \mathrm{Sr} /{ }^{86} \mathrm{Sr}$ ratio has been increasingly used as an optimal geographical fingerprint for food and animals [92]. For instance, numerous works on German [3], French [4], Italian [5] and Argentinean [93] wines have demonstrated a significant correlation between the value of ${ }^{87} \mathrm{Sr} /{ }^{86} \mathrm{Sr}$ in wines and their respective values in soils. In the same way, $\mathrm{Sr}$ isotopes in Reunion and New Caledonian coffee beans appear to be correlated with the geological patterns of their country of origin [6]. Consequently, the use of ${ }^{87} \mathrm{Sr} /{ }^{86} \mathrm{Sr}$ isotopic ratio as geographical traceability marker could be of great interest in the PDO olive oils authentication.

To our knowledge, such ${ }^{87} \mathrm{Sr} /{ }^{86} \mathrm{Sr}$ studies do not exist on any vegetable oil, probably because of analytical issues. Indeed, a vegetable oil (including olive oils) is a complex matrix with higher viscosity and organic load that the food products cited earlier. In addition, olive oils seem characterized by low $\mathrm{Sr}$ content [65]. The development of a specific methodology of $\mathrm{Sr}$ purification thus has to be performed prior to $\mathrm{Sr}$ isotopic ratio analysis. This issue, and the possibility to performed ${ }^{87} \mathrm{Sr} /{ }^{86} \mathrm{Sr}$ analyses on olive oil samples, will be the object of a future paper [Medini et al., Methodological development for ${ }^{87} \mathrm{Sr} /{ }^{86} \mathrm{Sr}$ measurement in olive oil-application for geographical traceability of PDO Nimes (France)].

\section{Conclusion}

At the present time, recognition of food authenticity is an important issue in terms of economic aspects and possible sanitary risks. Consequently, control tools are defined to 
insure a real traceability from the producer to the consumer. The scientific work on the authenticity and quality of olive oil is an ever-growing area, and studies commented upon throughout this review evidenced that both organoleptic assessment and analytical methods are important to establish the quality and the origin of PDO olive oils.

Negative sensorial attributes may be connected to fermentive alteration and then to low-quality oils. Discriminate oils specificities for trained assessors may be a way to detect adulteration and mislabeling. In addition, specificities in olive oil composition may also be interpreted as "marker" to insure product authenticity. Numerous studies reported on use of various analytical tools for discrimination of PDO products regarding (1) volatiles compounds, (2) fatty acid and triacylglycerol composition, (3) trace elements and/or (4) SIRs. However, no specific chemical parameter revealed really set for PDO traceability and authentication of olive oils since this review evidenced that the current methods allow discrimination of PDO olive oils, eventually from adulterated oils, but do not provide clear geographical indications. Indeed, basing on the traditional methods, discrimination seems sometimes possible between olive oils from different countries, but at the moment, no analytical tool is effective in discriminating the PDO origin for oils from two near regions of production. Consequently, further research is necessary to insure a real control on the labeling system, such as PDO's, protecting olive oils on a geographical basis and the use of $\mathrm{Sr}$ isotopic ratios could here provide promising results. ${ }^{87} \mathrm{Sr} /{ }^{86} \mathrm{Sr}$ signature revealed an optimal geographical fingerprint in the same purpose for other food products like cereals, orange juice, coffee or alcoholic beverages and thus could be a promising alternative to existing methods for the characterization of PDO olive oils, even if the development of a specific methodology of $\mathrm{Sr}$ purification has to be performed.

Acknowledgments The authors are indebted to the two reviewers who helped improve the manuscript, and especially would like to thank Nicola Caporaso for his constructive comments. This study has been carried out with support from the "Centre de Recherche et d'Enseignement de Géosciences de l'Environnement" and the "Université de Nîmes".

\section{Conflict of interest None.}

Compliance with Ethics Requirements This article does not contain any studies with human or animal subjects.

\section{References}

1. European Commission Regulation (1992). EEC No. 2081/92 on the protection of geographical indications and designations of origin for agriculture products and foodstuffs. Off J Eur Commun, L208

2. Kawasaki A, Oda H, Hirata T (2002) Determination of strontium isotope ratio of brown rice for estimating its provenance. Soil Sci Plant Nutr 48:635-640

3. Horn P, Schaaf P, Holbach B, Hoelxl S, Eschnauer H (1993) ${ }^{87} \mathrm{Sr}$ and ${ }^{86} \mathrm{Sr}$ from rock and soil into vine and wine. Zeitschrift fur Lebensmittel-Untersuchung und-Forschung 196:407-409

4. Barbaste M, Robinson K, Guilfoyle S, Medina B, Lobinsky R (2002) Precise determination of the strontium isotope ratios in wine by inductively coupled plasma sector field multicollection mass spectrometry (ICP-SF-MC-MS). J Anal At Spectrom 17:135-137

5. Durante C, Baschieri C, Bertacchini L, Cocchi M, Sighinolfi S, Silvestri M, Marhetti A (2013) Geographical traceability based on ${ }^{87} \mathrm{Sr} /{ }^{86} \mathrm{Sr}$ indicator: a first approach for PDO Lambrusco wines from Modena. Food Chem 141:2779-2787. doi:10.1016/j.foodchem.2013.05.108

6. Techer I, Lancelot J, Descroix F, Guot B (2011) About Sr isotopes in coffee «Bourbon Pointu» of the Réunion Island. Food Chem 126:718-724

7. Stewart B, Capo RC, Chadwick OA (1998) Quantitative strontium isotope models for weathering, pedogenesis and biogeochemical cycling. Geoderma 82:173-195

8. Anania G, Pupo D'Andra MR, (2008) The global market for olive oil: actors, trends, policies, prospects and research needs. TRADEAG-Agricultural Trade Agreements-working papers

9. Buckland G, Gonzalez CA (2010) Trends in olive oil production, supply and consumption in Mediteranean countries from 1961 to present day. In: Preedy VR, Watson RR (eds) Olives and olive oil in health and disease prevention. Academic Press, London, pp 689-698

10. European Commission Regulation (2009) EEC No. 182/2009 on the marketing standards for olive oil. Off J Eur Commun L63

11. Perri E, Benincasa C, Muzzalupo I (2012) Olive oil traceability. In: Olive germplasm - the olive cultivation, table olive and olive oil industry in Italy. http://www.intechopen.com/download/get/ type/pdfs/id/41344

12. International Olive Council (2011) Sensory analysis of olive oil. Method for the organoleptic assessment of virgin olive oil. COI/T. 20/Doc. No 15/Rev 4:1-14

13. European Commission Regulation (1991) EEC No. 2568/91 of 11 July 1991 on the characteristics of olive oil and olive-residue oil and on the relevant methods of analysis, and subsequent amendments. Off J Eur Commun L248:1-102

14. García JM, Seller S, Pérez-Camino MC (1996) Influence of fruit ripening on olive oil quality. J Agric Food Chem 44:3516-3520

15. Luchetti F (2000) Introduction. In: Harwood J, Aparicio R (eds) Handbook of olive oil-analysis and properties. An Aspen Publication, Gaithersburg, pp 1-16

16. Perez-Camino MC, Moreda W, Mateos R, Cert A (2002) Determination of easters of fatty acids with low molecular weight alcohols in olive oils. J Agric Food Chem 50:4721-4725

17. Gomez-Coca RB, Moreda W, Perez-Camino MC (2012) Fatty acid alkyl esters presence in olive oil vs organoleptic assessment. Food Chem 135:1205-1209. doi:10.1016/j.foodchem.2012.05.053

18. Lopez-Feria S, Cardenas S, Garcia-Mesa JA, FernandezHernandez A, Valcarcel M (2007) Quantification of the intensity of virgin olive oil sensory attributes by direct coupling headspacemass spectrometry and multivariate calibration techniques. J Chromatogr A 1147:144-152. doi:10.1016/j.chroma.2007.02.107

19. Lawless HT (1999) Descriptive analysis of complex odors: reality, model or illusion? Food Qual Prefer 10:325-332 
20. Flath RA, Forrey RR, Guadagni DG (1973) Aroma components of olive oil. J Agric Food Chem 21:948-952. doi:10.1021/jf601 90a030

21. Aparicio R, Morales MT, Alonso MV (1996) Relationship between volatile compounds and sensory attributes of olive oils by the sensory wheel. J Am Oil Chem Soc 73:1253-1264

22. Procida G, Giomo A, Cichelli A, Conte LS (2005) Study of volatile compounds of defective virgin olive oils and sensory evaluation: a chemometric approach. J Sci Food Agric 85:2175-

2183. doi:10.1002/jsfa.2122

23. Kalua CM, Allen MS, Bedgood DR Jr, Bishop AG, Prenzler PD, Robards K (2007) Olive oil volatile compounds, flavor development and quality: a critical review. Food Chem 100:273286. doi:10.1096/j.foodchem.2005.09.059

24. Cosio MS, Ballabio D, Benedetti S, Gigliotti C (2006) Geographical origin and authentication of extra virgin olive oils by an electronic nose in combination with artificial neural networks. Anal Chim Acta 567:202-210

25. Haddi Z, Amari A, Ali AO, Bari NE, Barhoumi H, Maaref A, Jaffrezic-Renault N, Bouchikhi B (2011) Discrimination and identification of geographical origin virgin oil by an e-nose based on MOS sensors and pattern recognition techniques. Proced Eng 25:1137-1140

26. Zunin P, Boggia R, Lanteri S, Leardi R, De Andreis R, Evangelisti $F$ (2004) Direct thermal extraction and gas chromatographic-mass spectrometric determination of volatile compounds of extra-virgin olive oils. J Chromatogr A 1023:271-276

27. Cavalli JF, Fernandez X, Lizzani-Cuvlier L, Loiseau AM (2004) Characterization of volatile compounds of French and Spanish virgin olive oils by HS-SPME: identification of quality-freshness markers. Food Chem 88:151-157

28. Cimato A, Dello Monaco D, Distante C, Epifani M, Siciliano P, Taurino AM, Zuppa M, Sani G (2006) Analysis of single-cultivar extra-virgin olive oils by means of an electronic nose and HSSPME/GC/Ms methods. Sens Actuators, B 114:674-680. doi:10.1016/j.snb.2005.06.058

29. Cajka T, Riddellova K, Klimankova E, Cerna M, Pudil F, Hajslova J (2010) Traceability of olive oil based on volatiles pattern and multivariate analysis. Food Chem 121:282-289

30. Morales MT, Luna G, Aparicio R (2005) Comparative study of virgin olive oil sensory defects. Food Chem 91:293-301

31. Angerosa F, Basti C, Vito R (1999) Virgin olive oil volatile compounds from lipoxygenase pathway and characterization of some Italian cultivars. J Agric Food Chem 47(3):836-839. doi:10.1021/jf980911g

32. Lorenzo IM, Perez Pavon JL, Fernandez Laespada ME, Garcia Pinto C, Moreno Cordero B (2002) Detection of adulterants in olive oil by headspace-mass spectrometry. J Chromatogr A 945:221-230. doi:10.1016/S0021-9673(01)01502-3

33. Pena F, Cardenas S, Gallego M, Valcarcel M (2005) Direct olive oil authentification: detection of adulteration of olive oil with hazelnut oil by direct coupling of headspace and mass spectrometry, and multivariate regression techniques. J Chromatogr A 1074:215-221. doi:10.1016/j.chroma.2005.03.081

34. Pena F, Cardenas S, Gallego M, Valcarcel M (2004) Direct screening of olive oil samples for residual benzene hydrocarbon compounds by headspace-mass spectrometry. Anal Chim Acta 526:77-82. doi:10.1016/j.aca.2004.07.073

35. Cerrato Oliveros C, Boggia R, Casale M, Armanino C, Forina M (2005) Optimization of a new headspace mass spectrometry instrument: discrimination of different geographical origin olive oils. J Chromatogr A 1076:7-75. doi:10.1016/j. chroma.2005.04.020
36. Cosio MS, Ballabio D, Benedetti S, Gigliotti C (2007) Evaluation of different storage conditions of extra virgin olive oils with an innovative recognition tool built by means of electronic nose and electronic tongue. Food Chem 101:485-491

37. Panagoua EZ, Sahgal N, Magan N, Nychas GJE (2008) Table olives volatile fingerprints: potential of an electronic nose for quality discrimination. Sens Actuators, B 134:902-907

38. Escuderos ME, Garcia M, Jimenez A, Horrillo MC (2013) Edible and non-edible olive oils discrimination by the application of a sensory olfactory system based on tin dioxide sensors. Food Chem 136:1154-1159. doi:10.1016/j.foodchem.2012.09.051

39. Tsimidou M, Karakostas K (1993) Geographical classification of Greek virgin olive oil by non-parametric multivariate evaluation of fatty acid composition. J Sci Food Agric 62:253-257. doi:10.1 002/jsfa.2740620308

40. Ollivier D, Artaud J, Pinatel C, Durbec JP, Guerere M (2003) Triacylglycerol and fatty acid compositions of French virgin olive oils. Characterization by chemometrics. J Agric Food Chem 51:5723-5731

41. Aranda F, Gomez-Alonso S, Rivera del Alamo RM, Salvador MD, Fregapane G (2004) Triglyceride, total and 2-position fatty acid composition of Cornicabra virgin olive oil: comparison with other Spanish cultivars. Food Chem 86:485-492

42. Ollivier D, Artaud J, Pinatel C, Durbec JP, Guerere M (2006) Differentiation of French virgin olive oil RDOs by sensory characteristics, fatty acid and triacylglycerol compositions and chemometrics. Food Chem 97:382-393

43. Tapp HS, Defernez M, Kemsley EK (2003) FTIR spectroscopy and multivariate analysis can distinguish the geographic origin of extra virgin olive oils. J Agric Food Chem 51:6110-6115

44. Bendini A, Cerretani L, Di Virgilio F, Belloni P, BonoliCarbognin M, Lercker G (2007) Preliminary evaluation of the application of the FTIR spectroscopy to control the geographic origin and quality of virgin oils. J Food Qual 30:424-437. doi:10.1111/j.1745-4557.2007.00132.x

45. De Luca M, Tarouzi W, Ioele G, Kzaiber F, Oussama A, Olivierio F, Tauler R, Ragno G (2011) Derivative FTIR spectroscopy for cluster analysis and classification of morocco olive oils. Food Chem 124:1113-1118. doi:10.1016/j.foodchem.2010.07.010

46. Christy AA, Kasemsumran S, Du Y, Ozaki Y (2004) The detection and quantification of adulteration in olive oil by near-infrared spectroscopy and chemometrics. Anal Sci 20:935-940

47. Yang H, Irudayaraj J, Paradkar MM (2005) Discriminant analysis of edible oils and fats by TIR, FT-NIR and FT-Raman spectroscopy. Food Chem 93:25-32. doi:10.1016/j.foodchem.2004.08.039

48. Galtier O, Dupuy N, Le Dreau Y, Ollivier D, Pinatel C, Kister J, Artaud J (2007) Geographic origins and compositions of virgin oils determinated by chemometric analysis of NIR spectra. Anal Chim Acta 595:136-144. doi:10.1016/j.aca.2007.02.033

49. Beaten V, Meurens M (1996) Detection of virgin olive oil adulteration by Fourier transform Raman spectroscopy. J Agric Food Chem 44:2225-2230

50. Jenkins R (1999) X-ray fluorescence spectrometry, 2nd edn. Wiley, New York

51. Bortoleto GG, Pataca LCM, Bueno MIMS (2005) A new application of X-ray scattering using principal component analysis - classification of vegetable oils. Anal Chim Acta 539:283-287

52. Pizarro C, Rodriguez-Tecedor S, Perez-del-Notario N, EstebanDiez I, Gonzalez-Saiz JM (2013) Classification of Spanish extra virgin olive oils by data fusion of visible spectroscopic fingerprints and chemical descriptors. Food Chem 138:915-922. doi:10.1016/j.foodchem.2012.11.087 
53. Urbano M, Luque De Castro MD, Perez PM, Garcia-Olmo J, Gomez-Nieto MA (2006) Ultraviolet-visible spectroscopy and pattern recognition methods for differentiation and classifications of wines. Food Chem 97:166-175

54. Souto UTCP, Pontes MJC, Silva EC, Galvao RKH, Araujo MCU, Sanches FAC, Cunho FAS, Oliveira MSR (2010) UV-visible spectrometric classification of coffees by SPA-LDA. Food Chem 119:368-371. doi:10.1016/j.foodchem.2009.05.078

55. Gonzalvez A, Armenta S, De La Guardia M (2009) Trace-element composition and stable isotope ratio for discrimination of foods with protected designation of origin. Trend Anal Chem 28:12951311

56. Baxter MJ, Crews HM, Dennis MJ, Goodall I, Anderson D (1997) The determination of the authenticity of wine from its trace element composition. Food Chem 60:443-450. doi:10.1016/ S0308-8146(96)00365-2

57. Monaci F, Bargagli R, Focardi S (2003) Element concentrations in Chianti Classico appellation wines. J Trace Elem Med Biol 17:4550

58. Anderson KA, Magnuson BA, Tschirgi ML, Smith B (1999) Determining the geographic origin of potatoes with trace metal analysis using statistical and neural network classifiers. J Agric Food Chem 47:1568-1575. doi:10.1021/jf980677u

59. Padin PM, Pena RM, Garcia S, Iglesias R, Barro S, Herrero C (2001) Characterization of Galician (N.W. Spain) quality brand potatoes: a comparison study of several pattern recognition techniques. Analyst 126:97-103. doi:10.1039/b007720h

60. Di Giacomo F, del Signore A, Giaccio M (2007) Determining the geographic origin of potatoes using mineral and trace element content. J Agric Food Chem 55:860-866. doi:10.1021/jf062690h

61. Anderson KA, Smith B (2005) Use of chemical profiling to differentiate geographic growing origin of raw pistachios. J Agric Food Chem 53:410-418. doi:10.1021/jf048907u

62. Del Signore A, Di Giacomo F, Giaccio M (2004) Determinating the regional origin of cheeses with trace metal analysis using statistical classifiers. J Commod Sci 43:133-144

63. Jimenez MS, Velarte R, Gomez MT, Castillo JR (2004) Multielement determination using on-line emulsion formation and ICP-MS/FAAS for the characterization of virgin oils by principal component analysis. Atomic Spectrom 25:1-12

64. Zeiner M, Steffan I, Cindric IJ (2005) Determination of trace elements in olive oil by ICP-AES and ETA-AAS: a pilot study on the geographical characterization. Microchem J 81:171-176. doi:10.1016/j.microc.2004.12.002

65. Benincasa C, Lewis J, Perri E, Sindona G, Tagarelli A (2007) Determination of trace element in Italian virgin oilive oils and their characterization according to geographical origin by statistical analysis. Anal Chim Acta 585:366-370. doi:10.1016/j.aca.2006.12.024

66. Carmen CV, Bouzas PR, Oliveras-López MJ (2012) Determination of trace elements in extra virgin olive oils: a pilot study on the geographical characterization. Food Chem 134:434439

67. Araghipour N, Colineau J, Kot A, Akkermans W, Rojas JMM, Beauchamp J, Wisthaler A, Mark TD, Downey G, Guillou C, Mannina L, Van Ruth S (2008) Geographical origin classification of olive oils by PTR-MS. Food Chem 108:374-383. doi:10.1016/j.foodchem.2007.10.056

68. Farhan FM, Rammati H, Ghazi-Moghadam G (1988) Variation of trace metal content of edible oils and fats during refining processes. J Am Oil Chem Soc 65:1961-1962

69. Le Coco F, Ceccon L, Ciraolo L, Novelli V (2003) Determination of cadnium(II) and zinc(II) in olive oils by derivative potentiometric stripping analysis. Food Control 14:55-59
70. Giacomo D, La Pera L, Giuffrida D, Salvo F, Lo Turco V (2004) Influence of the olive variety and the zone of provenience on selenium content determined by cathodic stripping potentiometry (CSP) in virgin olive oils. Food Chem 88:135-140. doi:10.1016/j.foodchem.2033.12.036

71. D'Imperio M, Dugo G, Alfa M, Mannina L, Segre AL (2007) Statistical analysis on sicilian olive oils. Food Chem 102:956965. doi:10.1016/j.foodchem.2006.03.003

72. Lerma-Garcia MJ, Ramis-Ramos G, Herrero-Martinez JM, SimoAlfonso EF (2010) Authentication of extra virgin olive oils by Fourier-transform infrared spectroscopy. Food Chem 118:7883. doi:10.1016/j.foodchem.2009.04.092

73. Calderone G (2005) Applications des techniques istopiques moderns pour la caractérisation de produits alimentaires et de boissons. PhD dissertation, University of Nantes, France. pp 252

74. Camin F, Larcher R, Nicolini G, Bontempo L, Bertoldi D, Perini M, Schlicht C, Schellenberg A et al (2010) Isotopic and elemental data for tracing the origin of European olive oils. J Agric Food Chem 58:570-577

75. Royer A, Gerard C, Naulet N, Lees M, Martin GJ (1999) Stable isotope characterization of olive oils. I-compositional and carbon-13 profiles of fatty acids. J Am Oils Chem Soc 76:357-363

76. Angerosa F, Breas O, Contento S, Guillou C, Reniero F, Sada E (1999) Application of stable isotope ratio analysis to the characterization of the geographical origin of olive oils. J Agric Food Chem 47:1013-1017. doi:10.1021/jf9809129

77. Mannina L, Patumi M, Proietti N, Bassi D, Segre AL (2001) Geographical characterization of Italian virgin olive oil using high field ${ }^{1} \mathrm{H}$ NMR spectroscopy. J Agric Food Chem 49:2687-2696

78. Vlahov G, Del Re P, Simone N (2003) Determination of geographical origin of olive oils using 13C nuclear magnetic resonance spectroscopy. I-classification of olive oils of the Puglia region with denomination of protected origin. J Sci Food Agric 51:5612-5615

79. Rezzi S, Axelson DE, Heberger K, Reniero F, Mariani C, Guillou $\mathrm{C}$ (2005) Classification of olive oils using high throughput flow ${ }^{1} \mathrm{H}$ NMR fingerprinting with principal component analysis, linear discriminant analysis and classification probabilistic neural networks. Anal Chim Acta 552:13-24

80. Alonso-Salces RM, Moreno-Rojas JM, Holland MV, Reniero F, Guillou C, Heberger K (2010) Virgin olive oil authentication by multivariate analyses of ${ }^{1} \mathrm{H}$ fingerprints and $\delta^{13} \mathrm{C}$ and $\delta^{2} \mathrm{H}$ data. $\mathrm{J}$ Agric Food Chem 58:5586-5596

81. Longobardi F, Ventrella A, Napoli C, Humpfer E, Schutz B, Schafer MG, Kontominas MG, Sacco A (2012) Classification of olive oils according to geographical origin by using ${ }^{1} \mathrm{H}$ NMR fingerprinting combined with multivariate analysis. Food Chem 130:177-183

82. Petrakis PV, Agiomyrgianaki A, Christophoridou S, Spyros A, Dais P (2008) Geographical characterization of greek virgin olive oils (cv. Koroneiki) using $1 \mathrm{H}$ and 31P NMR fingerprinting with canonical Discriminant analysis and classification binary trees. J

Agric Food Chem 56:3200-3207

83. Dais P, Hatzakis E (2013) Quality assessment and authentication of virgin olive oil by NMR spectroscopy: a critical review. Anal Chim Acta 765:1-27. doi:10.1016/j.aca.2012.12.003

84. Rossmann A, Haberhauer G, Holzl S, Horn P, Pichlmayer F, Voerkelius S (2000) The potential of multielement stable isotope analysis for regional origin assignment of butter. Eur Food Res Technol 211:32-40

85. Fortunato G, Mumic K, Wunderli S, Pillonel L, Bosset JO, Gremaud G (2004) Application of strontium isotope abundance ratios measured by MC-ICP-MS for food authentication. J Anal At Spectrom 19:227-234 
86. Kelly S, Baxter M, Chapman S, Rhodes C, Dennis J, Brereton P (2002) The application of isotopic and elemental analysis to determine the geographical origin of premium long grain rice. Eur Food Res Technol 214:72-78

87. Asfaha DG, Quetel CR, Thomas F, Horacek M, Wimmer B, Heiss $\mathrm{G}$ et al (2011) Combining isotopic signatures of $n(87 \mathrm{Sr}) / n(86 \mathrm{Sr})$ and light stable element $(\mathrm{C}, \mathrm{N}, \mathrm{O}, \mathrm{S})$ with multi-elemental profiling for the authentication of provenance of European cereal samples. J Cereal Sci 53:170-177

88. Franke BM, Koslitz S, Micaux F, Piantini U, Maury V, Pfammatter E, Wunderli S, Gremaud G, Bosset JO, Hadorn R, Kreuzer M (2008) Tracing the geographic origin of poultry meat and dried beef with oxygen and strontium isotope ratios. Eur Food Res Technol 226:761-769

89. Rummel S, Hoelzl S, Horn P, Rossmann A, Schlicht C (2010) The combination of stable isotope abundance ratios of $\mathrm{H}, \mathrm{N}$ and $\mathrm{S}$ with $87 \mathrm{Sr} / 86 \mathrm{Sr}$ for geographical origin assignment of orange juices. Food Chem 118:890-900. doi:10.1016/j.foodchem.2008.05.115

90. Weckerley B, Richling E, Heinrich S, Schreier P (2002) Origin assessment of green coffee (Coffea arabica) by multi-element stable isotope analysis of caffeine. Anal Bioanal Chem 374:18451850

91. Parker IG, Kelly SD, Sharman M, Dennis MJ, Howie D (1998) Investigation into the use of carbon isotope ratios (13C/12C) of Scotch whisky congeners to establish brand authenticity using gas chromatography-combustion-isotope ratio mass spectrometry. Food Chem 32:423-428

92. Kelly S, Heaton K, Hoogewerff J (2005) Tracing the geographical origin of food: the application of multi-element and multi-isotope analysis. Trends Food Sci Technol 16:555-567

93. Di Paola-Narajo RD, Baroni MV, Podio NS, Rubinstein HR, Fabani MP, Badini RG, Inga M, Ostera HA, Cagnoni M, Gallegos E, Gautier E, Peral-Garcia P, Hoogewerff J, Wunderlin WA (2011) Fingerprints for main varieties of Argentinean wines: terroir differentiation by inorganic, organic and stable isotopic analyses coupled to chemometrics. J Agric Food Chem 59:7854-7865 